\title{
Action-Research in the Student Voice Perspective: the Fourth Year Upper Secondary School Class Case
}

\author{
Rosanna Tammaro (corresponding author) \\ Dept. of Human, Philosophical and Education Sciences, University of Salerno \\ Road Giovanni Paolo II, Fisciano 84084, Italy \\ Tel: 089-964345 E-mail: rtammaro@unisa.it
}

Marika Calenda

Dept. of Human, Philosophical and Education Sciences, University of Salerno

Road Giovanni Paolo II, Fisciano 84084, Italy

Tel: 089-962621Ｅ-mail: macalenda@unisa.it

Annamaria Petolicchio

Dept. of Human, Philosophical and Education Sciences, University of Salerno

Road Giovanni Paolo II, Fisciano 84084, Italy

Tel: 089-962621Ｅ-mail: annamariapetolicchio@gmail.com

Iolanda Sara Iannotta

Dept. of Political, Social and Communication Sciences, University of Salerno

Road Giovanni Paolo II, Fisciano 84084, Italy

Tel: 089-962621_E-mail: iiannotta@unisa.it

Received: June 2, 2015 Accepted: June 24, 2016 Published: July 8, 2016

doi:10.5296/jet.v3i2.9749 URL: http://dx.doi.org/10.5296/jet.v3i2.9749 


\section{Abstract}

This paper describes a study that is currently being carried out in an Upper Secondary School in the Province of Salerno (Campania, Italy). Using the Student Voice approach, the research group of the University of Salerno started the study with the aim of spreading the culture of participation and the active involvement of students in school life, while also strengthening their role as active decision-makers in the teaching/learning processes. This research is divided into two stages: an exploratory phase, that is currently being carried out and interests only one fourth year class of a Second Level College of Science: we define this phase our pilot study. Subsequently, based on critical situation and results of the first phase, the aim is to include a larger number of students. The pilot study involves 22 students of a fourth year class and deals with the problems of inattention and lack of interest that, in general, students demonstrate towards school activities. The main purposes of this first phase are: to gather information and to analyse the reasons for this recurring behavior; to implement, with the Student Voice approach, resolved strategies, as well as, verify their effectiveness; and based on this study's results, we want to involve a larger number of students, if possible, during the next school year (2016/2017). The aim is to establish a different relationship with students, promoting dialogue and debate with teachers, to bring out their points of view, their wishes, the expectations they have towards the school, in order to integrate their concerns in the decisions which affect them. The approach used in this study is qualitative-hermeneutic; an Italian schoolteacher that is co-author of this paper, with the support of the research group, carried out the Action-Research; the data are the result of the observations, group discussions and comparisons. First, a questionnaire was developed to find initial information regarding the students' opinion about the use of technologies for didactic activities, suggestions and preferences on learning. Subsequently, a qualitative data analysis was carried out, useful to achieve new information for research continuance, specifically to construct the instrument that will be used in the second phase.

Keywords: Student Voice, Democratic Participation, Upper Secondary School

\section{Introduction}

European legislation in the field of young people is rich and varied. For decades, it has been recommending priorities, such as the development of human capital, promoting active citizenship and youth participation in the different contexts of life: social, economic and cultural. Among the most recent and significant regulations, it is possible to include the Council Resolution of 27 November 2009 on an European Cooperation in the Youth Field (2010-2018), (2009/C 311/01) developed with the direct involvement of young people as a result of the Lisbon Strategy. European cooperation in the youth field for the period between 2010-2018 aims to improve the cooperation between EU Countries to provide better opportunities for young people. In particular, the main objective of this renewed framework, or "EU youth strategy", is "to improve the efficiency of the cooperation and actions already put in place and provide increased benefits to young people in the EU" (2009/C 311/01). This strategy has two main objectives: to provide more and equal opportunities for young people in the education path and in the labour market and, to encourage young people to actively 
participate in the knowledge society. The privileged tool for reaching these objectives is the dialogue between young people and policy makers, in order to increase active citizenship, promote social inclusion and ensure the insertion of young people in EU policy making. The ventures with young people concern eight specific fields: education and training, employment and entrepreneurship, health and wellness, participation of young people in the EU democratic process and in society (in the context of a specific EU structured dialogue), voluntary activities, social inclusion, youth and the world with actions to help young people to engage themselves outside the EU or become more involved in areas as climate change, international cooperation and human rights, creativity and culture (2009/C 311/01). This resolution adopted the recommendations contained in the Communication from the Commission to the Council, the European Parliament, the European Economic and Social Committee and the Committee of the Regions of: An EU Strategy for Youth: Investing and Empowering - A renewed open method of coordination to address youth challenges and opportunities. Another key document is the European Commission Communication of 16 December 2008 on New Skills for New Jobs. Anticipating and matching labor market and skills needs. The Recommendation of the European Parliament and of the Council of 18 December 2006 on Key Competences for Lifelong Learning is also very important. The document (2006/962/EC) contains the European reference framework for identifying the key competences for lifelong learning. The framework outlines eight skills that everyone needs for personal fulfillment and development, active citizenship, social inclusion and employment. The competences are all equally important and this includes the possession of certain capabilities, already described by DeSeCo, needed to live in the knowledge society, such as: communication in the mother-tongue, communication in foreign languages, mathematical competence and basic competences in the science and technology field, digital competence, learning to learn, social and civic competences, a sense of initiative and entrepreneurship, cultural awareness and expression. These are just some of the considerations that emerge from the numerous documents on this subject, in the European context, about the youth's role in the society, in relation to the processes of change and renewal of the institutions. The general framework highlights a fundamental strategy that refers to the need to support, in every way possible, initiatives aimed at encouraging young people to become active citizens and participate in social processes, in order to support the expression of their opinions, to build those democratic processes that are bases of the Europe's future.

\section{Student Voice: Listening to Student to Improve Education}

For many years already, numerous studies in education observe the importance of participation, involvement and listening to young people about the teaching and learning processes. In fact, many studies highlight the need, felt by young people, to be able to have more opportunities to express their views. Furthermore, they raise the problem of how actually make young people protagonists of the global change processes affecting the society and, in particular, school (Slater, 2012; Smyth, 2006). Despite the proliferation of recommendations, conclusions, documents that address youth policy and those related to education and inclusion, young people are disenchanted and they feel that policies do not fully meet their needs. For this reason, they are favorable towards the discovery of a model of 
participatory democracy, closer to the classical tradition, which is based on the common good, on popular involvement in decision-making, in the freedom to express their opinion without fear of the decision maker (Fielding, 2012). This position can also be transferred to the classroom context, where the idea that it is necessary to give students a more involved role and responsibility in decision-making through space to express their own points of view is becoming more widespread. The school environment, however, often prevents any form of expression and youth involvement. In effect, some research has indicated the difficulties that young people have when considering school as a welcoming place, where they can go through wellness experiences and where they can talk and express themselves, their aspirations, their wishes and their points of view, in an open and peaceful way (Smyth \& McInerney, 2012). Currently (and not only in Italy), learning environments characterized by a managerial logical are predominant, and a kind of reporting evaluation comes between the formative evaluation; this phenomenon involves the orientation towards the efficiency of the system. Weiner (2003) used the metaphor of the "courtroom" to describe this kind of classroom, where the teacher is seen as an administrator of justice and where students act according to their extrinsic motivation, to avoid penalties and punishments. The author proposes to turning this perspective upside down, calling for the diffusion of a different kind of social practice in school environments; the desired situation, very different from the previous one, held in the metaphor of the school as a "temple of learning". In the formal learning context, relationships are equal, based on respect and recognition of the importance of the others, built through dialogue, discussion and cooperation. One of the perspectives of the Student Voice construct focuses on teaching/learning processes. Flutter and Rudduck (2004) have shown that students are capable of assuming their entrusted responsibilities and are able to collaborate with teachers in the choice of strategies, to reinforce and facilitate their learning. The perspective is overturned: students are no longer perceived as mere "users" or "clients" of a service, but as active participants and co-managers of the learning processes. «In democratic organizations [...] such organizational shaping is never just a top-down process but is an engaged process involving all organizational players. The dialectical, relational view of leadership as a process incorporates the human agency of all members of the organization. These inevitably interact with each other and with the simultaneously enabling and constraining (enabling in some ways and constraining in others) norms, practices, and structures of the organization. Democratic and transformative leadership takes place in such environments, which are dynamic rather than static, and which themselves are located in complex social and political contexts. Such leadership arises not from coercion and manipulation, but from relational collaborative, participatory processes. In fact, the importance of the relational nature of schooling generally, and particularly of the student-teacher relationship, is a key theme of several of the articles in this special issue» (Angus, 2006, p. 372).

\section{Research Methodology: Context, Sample and Objectives}

Based on the aforementioned theoretical framework, we intend to structure an empirical research with the aim of giving voice to students of a Upper Secondary School; their viewpoints tell us their idea of school and, especially, their idea of a quality school. The 
purpose of this research is to create an inclusive environment in the class, in which the students are involved in decision-making, as representative of particular interests, to participate both in the reflection on their educational path and, at the same time, in the educational path planning. The research, currently being carried out, involves students and teachers of a Fourth Year Class of the Second Level College of Science "Alfonso Gatto" in Agropoli (Province of Salerno, Italy). At the end of last academic year (2014/2015), during the final staff meeting, an alarming fact was revealed: the widespread insufficient interest and resulting passive attitude of most of the students to the school life. This significant scenario required consideration; for this reason, it was necessary to start a discussion among the teachers to identify possible solution strategies.

The main objectives of this research are:

- to encourage students to active participate in decision-making that affects them;

- to create an inclusive environment and facilitate horizontal communication between students and teachers;

- to listen to students' needs and try to meet their expectations;

- to oppose the apathy towards school life.

As previously described, at present, the educational research offers an interesting methodology to hinder such problems through the Student Voice approach. Starting from the theoretical premises provided by this approach, it was decided to structure a research project based on the experience described by Grion and Manca (2015) in which an important element of criticality emerges, in relation to the students gradual involvement. Initially, it was decided to involve only one class, composed of 22 students, 11 males and 11 females (including three couples of twins), with the intention to extend, at a later stage, the participation to a larger number of students. One of the authors of this paper, that is tenured teacher in the school, proposed to undertake an Action-Research path in one of her classes (III C), where the problem of the insufficient involvement of the students manifested itself more prominently. The Action-Research is a form of participatory research, carried out by people that are directly involved in the action within an institution, in order to solve a specific problem; this methodology combines the cognitive moment, aimed at the production of knowledge on a given educational reality, with the action, aimed at the implementation of an appropriate intervention plan (Trinchero, 2004). Therefore, its logic was perfectly consistent with the research and then, applicable in our context of analysis. During the final meeting held to assign the grades of the Third Year "C class", teachers evaluated how much the class appeared disinterested, passive and unmotivated. The problem, apart from cognitive results achieved, was of a motivational and participatory character. At the beginning of the academic year 2015/2016, strategies were sought that could interest students, making them feel protagonists and co-responsible for their educational path. As soon as the problem was highlighted - the lack of incentive and participation; the students passive fruition and the consequent teachers disinterest - an Action-Research path for the interested class was planned. Reclaiming the articulation in phases of the Action-Research (Notti, 2012), we accordingly organized our research: 
- $\quad$ identification of the problem to be solved;

- formulation of the hypotheses for change and objectives;

- $\quad$ application of the assumptions in the contexts of the formulated plan;

- evaluation and implementation of the changes to the methods used;

- consolidation of applications with positive assessment.

After having focus the problem and decided to follow the Student Voice approach, the second phase was to define the Action-Research objectives. Our intent was to explore the effectiveness of student involvement in the teaching/learning processes, to improve learning situations. We decide to use social media and digital technology to reduce the communication gap between learners and teachers and bring them to the world of young people.

To ensure that the learners will not receive the educational choices as imposed from teachers or policy makers, the teacher decided to directly involve students in the choice of subjects and methodologies to be used during the school year.

\section{Action-Research in Class}

After outlining the context, sample and objectives of our research, the operational phase (application) that began in September 2016 is described. At the beginning of the academic year 2015/2016, the teacher of Italian and Latin in the Fourth Year "Class C" and the members of the research group administered an orientation questionnaire, with exploratory purposes. Consistent with our research objectives, we provided an instrument that would allow to detect useful information to better focus the problem, in particular the areas examined with the questionnaire's items are: use of technologies, methodologies, interests, suggestions. The questionnaire consisted of eight questions, including five structured and three unstructured questions; the first three structured questions examined the use of technology, the fourth methodology to be used at school, the fifth contents of interest. The unstructured questions provided suggestions addressed to the teacher to organise a kind of participatory planning. Before its administration, the teacher explained to the class the reasons and purposes of the research; moreover, she explained the questionnaire content and provided clarification on it. The questionnaire is anonymous and self-administered; after being compiled, the teacher discussed with the class to better understand the reasons for their answers and to get additional information. Data analysis of the questionnaires showed that all the students have access to technology and internet, almost all of them want to interact with the teacher through technologies and all the students feel the need to be more involved in school life. Particularly, the situation that emerged from analysis is as follows: 20 students state to have their own personal computer, all of them have access to an internet connection (by phone), 17 students would choose to interact with the teacher using technologies, compared to one single student was not interested and 4 students pronounced their perplexity, fearing an excessive intrusion of the teacher in not purely academic moments. Regarding the question on methodologies, which provided a list of seven alternatives among which students could select up to a maximum of three, the most mentioned were four categories: concept 
maps, power point presentations, group works and frontal lectures. The question related to interests includes five alternatives and the opportunity to indicate two choices. The most interesting areas for the students were music and sport. Regarding the last three questions, we grouped the open answers into categories, based on the identified keywords. The open question "What would you like the school to offer you?", 10 answers fall into the category "cultural preparation, future and work"; 7 answers fall into the category "projects and extracurricular activities"; 2 answers concern the category "spaces and classrooms", one concerns the category "security". Nevertheless, it was impossible to include 2 answers into category and, for this reason, we report these entirely. The first student said "I think our school is well equipped compared to other schools, but there is not a good use of what it gives us". Whereas, the second student said "later the installation of interactive whiteboards, I think there is nothing to add". To the question "What would you suggest to the teacher to make lessons more participative and interesting?", 13 students suggested a greater use of technology and alternative methods to frontal lessons; 6 pupils suggested that teachers improve relationships with their students and encourage their involvement; 1 single student calls for more frontal lectures that tackles current events, one student said that lessons would have an educational purpose, one students answered "I do not know". To the question "Indicates a maximum of three themes that you should be dealt with during this school year", 9 students would like to explore themes related to the arts, especially music, 7 students state that they would like to devote to discussion on social problems such as immigration, Camorra, racism and discrimination, young problems, etc., 3 students indicate the detailed study of school subjects (like Italian and history), instead, 3 students suggest of dealing with more attention issues related to psychology and human sciences. We chose to report an answer that has particularly impressed us: "Absolutely music, because all of us young people spend much of our time listening music. Then I would leave space for love and dreams; this theme has always fascinated me so much". Based on the information obtained through the orientation questionnaire, the teacher planned a participatory planning, with a structure of the essential content but calibrated on the interests emerged and characterized by the students' involvement in the choice of methodologies and educational activities, favoring the use of technologies (interactive whiteboard, power point and blog). In line with this approach and encouraged by the attention towards them, the students proposed creating two chat groups on WhatsApp, to interact with each other and the teachers. For this, 4 hours for Mathematics and 3 hours for Physics and 4 hours for Italian and 3 for Latin were dedicated to the chat. The administrator of the two groups was a student and these groups were composed of all the students of the class, the teacher of Italian and Latin and the teacher of Maths and Physics. During the first period of the school year, the teacher of Italian and Latin was able to find that, as a result of innovations insertion in the teaching activities, since the beginning, interesting elements in relation to the students' attitude in the classroom emerged. The students expressed a greater participation and renewed interest in school life, they were more serene and supportive during the frontal lectures and more frequently launched discussions and asked to expand on some topics, demonstrating, as a whole, to be much more aware, active and participating. At this phase of our research, it was not our interest to comment specifically on the connection between this approach and the learning outcomes. In fact, the 
main purpose was to make the students protagonists of the educational project, not considering them as mere passive recipients and beneficiaries of the educational path dispensed.

The authors confirm that the purpose of this research was of an exploratory and descriptive nature, namely, our goal was to collect information to be able to organize, later, a more structured research path, which will involve a greater number of students. With the passing of the months, the teachers verified that the use of the chat groups had a strategic importance on the improvement of the relationships between the teachers and students; it has allowed to establish a more cooperative atmosphere in the classroom. In fact, if at first time, the chat groups were only used for service communications, later the students, after an initial resistance, started to communicate and exchange all kinds of information, without the fear of being judged: this helped to redefine, in a more equitable way, the relationship with the teachers. Before the mid-term evaluation, it was decided to ask the students how they were living through this time of change in class and, therefore, an open question was proposed, through which the students freely expressed their opinions. Specifically, the question was formulated as follows: "Do you think that technology and social media insertion was useful in improving the relationships within the class group?" A preliminary analysis of the answers highlighted very favorable opinions about the use of technologies. Positions that stress the positive impact on learning processes and relationships, as reflected in the answers which is shown below: "In my opinion, the use of social media in today's society, can be considered a positive factor, especially for didactic purposes". In fact, in recent years, in the school a new tool has entered, the interactive whiteboard (IWB) and lessons have undergone a change. The usual frontal lectures are integrated by the slides and are assigned to group projects that involve the use of social media. This promotes the viewpoints exchange and the opportunity to share one's own experience with others. In addition, with new media, through chat groups, we have the opportunity to exchange important information, for educational purposes with teachers and friends. "I believe that the interaction with media for the educational purposes is very useful, because it brings us closer to the subject and to other people and makes the gap between teacher and pupil much less clear; throughout our ideas and thoughts we can be more responsible and active in the educational path implementation". Reading over: "For example, with the group work on Orazio's Carpe Diem, I fully understand the writer's message, because the exchange of ideas among colleagues makes everything easier. Knowing that our thoughts will be read by many people makes us more involved to making a good job". "I think that method used recently adding social media are of service to put in contact teachers and students and to impassion us students to the subject. For example in the last group work, we used social media by writing a comment on the Orazio's Eleventh Ode and this has enabled us to debate with each other and to study better, even reading comments on blogs of other people".

\section{Conclusions}

The aspect that has most impressed us is that the entire class proves to be more active, participating and attentive during frontal lectures and learning activities that are carried out by teachers. The teachers have interpreted the initial closing as a sign of discomfort and, 
effectively, giving to the students a chance to assert their opinions about school life, to participate in important decisions, to use the methods they prefer, even students who appeared more passive and indifferent, are showing, on the contrary, to be assertive and interested. Clearly, this could be ascribable to a "novelty effect", but only at the end of this first phase of our research, can clarify us limits and criticalities. In addition, the effect of WhatsApp group was surprising, because, thanks to the communication facilitated by emoticons, the students showed more courage in expressing their needs and asking questions during homework (especially those of Maths). In some cases, the students asked to postpone tests or to deepen topics that are not clear, or asked the Maths' teacher to support them in their homework; often, even just a little hint is enough to carry on. The students do not want to feel cut off from the teaching/learning process, and to recognize the interest of teachers is producing a process of reconsideration of the importance of school life in them. It must be stressed that this is facilitated by the kind of approach that the teachers have with the students from peer-to-peer relationships and the effectiveness of communication. The facts in our possession show that the students are encouraged by the undertaken experience and this allows for the emergence of cause for reflection. The greater response to the teachers solicitations changes in the way the relationships between teachers and students are managed, now more equal, the discussions between peers and with teachers, the facilitation of the learning processes made possible by all the elements together and by less separation between the teachers and the class. Our work of qualitative and quantitative data collection and analysis that come from this initial phase of the Action-Research will continue until the end of the academic year, when it will be interesting to consider the students' learning outcomes. The aforementioned data will provide information elements useful for the research continuance as well as the construction of the instruments to be used in the subsequent phases.

\section{Acknowledgement}

The Headteacher of the Second Level College of Science "Alfonso Gatto", in Agropoli, supported this research. We are also grateful to all the teachers of the fourth year class, which with their compassion and friendliness, have contributed to our research implementation. We thank our colleague, Prof. Sasha A. Berardo, who provided insight and expertise that greatly assisted the research, especially in the English writing. We would also like to show our gratitude to all the students of a fourth year class that have been made the research possible.

\section{References}

Angus, L. (2006). Educational leadership and the imperative of including student voices, student interests, and students' lives in the mainstream. International Journal of Leadership in Education, 9(4), 369-379. http://dx.doi.org/10.1080/13603120600895544.

Fielding, M. (2012). Beyond Student Voice: Patterns of Partnership and the Demands of Deep Democracy, Revista de Educación, 359, 45-65. http://dx.doi.org/10.4438/1988-592X-RE-20 12-359-195

Flutter, J., \& Rudduck, J. (2004). Consulting Pupils. What's in it for schools?. London, UK: Routledge. 


\section{Macrothink}

Journal of Education and Training

ISSN 2330-9709

2016, Vol. 3, No. 2

Grion, V., \& Manca, S. (2015). Voci e silenzi in un'esperienza di Student Voice mediate dai social network, TD Tecnologie didattiche, 23(2), 70-80. Retrieved from http://www.tdjournal. itd.cnr.it/article/download/786/719.

Notti, A. M. (2012). La ricerca empirica in educazione. Metodi, tecniche e strumenti. San Cesario di Lecce: Pensa Editore.

Slater, R. O. (2012). Developmental democracy, accountability and educational leadership. International Journal of Leadership in Education: Theory and Practice, 15(3), 387-394. http://dx.doi.org/10.1080/13603124.2011.609603.

Smyth, J. (2006). Educational leadership that fosters 'student voice'. International Journal of Leadership in Education, 9(4), 279-284. http://dx.doi.org/10.1080/13603120600894216

Smyth, J., \& McInerney, P. (2012). From silent witnesses to active agents: Student voice in re-engaging with learning. New York, NY: Peter Lang.

Trinchero, R. (2004). I metodi della ricerca educativa. Roma-Bari: Editori Laterza.

Weiner, B. (2003). The classroom as a courtroom. Social Psychology of Education, 6(1), 3-15. http://dx.doi.org/10.1023/A:1021736217048.

European Parliament and the Council. (2006). Key Competences for Lifelong Learning. Retrieved from http://eur-lex.europa.eu/legal-content/EN/TXT/HTML/?uri=CELEX:32006H 0962\&from $=\mathrm{EN}$

Council Resolution. (2009). European Cooperation in the Youth Field (2010-2018). Retrieved from http://eur-lex.europa.eu/legal-content/EN/TXT/HTML/?uri=URISERV:ef0022\&from=EN

\section{Copyright Disclaimer}

Copyright reserved by the author(s).

This article is an open-access article distributed under the terms and conditions of the Creative Commons Attribution license (http://creativecommons.org/licenses/by/3.0/). 